\title{
繊維強化樹脂の伝熱解析を用いた 流動方向予測と構造解析との連成*
}

\author{
大石 智子*1, 坂 本 博夫*2, 青木 普 道*3
}

\section{Prediction of Flow Direction by Thermal Analysis and Coupling with Structural Analysis in FRP}

\author{
Satoko OISHI, Hiroo SAKAMOTO ${ }^{* 4}$ and Hiromichi AOKI \\ ${ }^{* 4}$ Advanced Technology R \& D Center, Mitsubishi Electric Corporation, \\ 8-1-1 Tsukaguchi-Honmachi, Amagasaki-shi, Hyogo, 661-8661 Japan
}

\begin{abstract}
Recently, the number of products made from fiber-reinforced plastics (FRP) has been increasing. due to their low cost, high rigidity, and high strength. Generally, injection molded FRP parts are known to be anisotropic, i.e. mechanical properties are different in the flow and transverse directions. Therefore, it is important to consider the flow direction during structural analysis and design for FRP products. In this study, a new method for structural analysis with consideration of flow direction is proposed. In this method, the flow analysis component was substituted with thermal analysis, whereby the flow direction was simply predicted on the basis of the direction of heat flux. Furthermore, it is easier to couple the thermal and structural analysis components and incorporate them into conventional software for structural analysis. In order to verify the prediction of flow direction by means of thermal analysis, fiber orientation was observed by X-ray CT. Verification was also conducted by performing static and modal analysis for a propeller fan. It was confirmed by means of fiber orientation observation that the heat flux direction was comparable to the resin flow direction. The results from both static and modal analysis with consideration of flow direction also agreed well with that of the actual product.
\end{abstract}

Key Words: Fiber-reinforced Plastics, Resin Flow, Fiber Orientation, Thermal Analysis, Structural Analysis, Static Analysis, Modal Analysis, Structural Design, Fan, CAE

\section{1. 緒言}

近年, 低コスト化・高剛性化・高強度化のために, 瀻維を含有した繊維強化樹脂 (fiber-reinforced plastics；FRP)を材料とする製品が増加している。一般 に，樹脂は異方性を有するため，射出成形に扔いてそ の流動方向 (Mold Direction；以下, MD) そその垂直 方向 (Transverse Direction；以下，TD）において弾 性率, 強度等の機械的特性が異なる。とくに, 瀻維強 化樹脂では，流動方向が機械的特性に及ぼす影響が大 きく(1) (4), 繊維強化樹脂製品の構造設計のためには, 流動方向を考慮した構造解析が不可欠である，その流 動状態を把握するためには，流動解析を実施するのが 一般的である(5) (8).

しかし，流動解析と構造解析のソフトウェアや使用 するメッシュが異なることから，流動解析結果の流動 方向を構造解析にマッピングする作業が必要になる.

* 原稿受付 2009 年 1 月 20 日.

*1 三菱電機 (株) 住環境研究開発センター(严 247-8501 鎌倉市 大船 5-1-1).

*2 正員, 三菱電機(株) 先端技術総合研究所(五 661-8661 尼崎 市塚口本町 8-1-1)

*3. 三菱電機(株) 中津川製作所(画 508-8666 中津川市駒場町 13).

E-mail : Sakamoto.Hiroo@aj.MitsubishiElectric.co.jp
このため, 新たなマッピングのソフトが必要になるこ と，マッピング作業に時間が必要になり，これまで流 動方向を考慮した構造解析はごく限られた例でしか実 現されていなかった ${ }^{(9)}$.また，流動方向が一様な状態 にある等方性材料とみなした構造解析においては，実 機と解析結果に大きな誤差が生じていた。

そこで, 本研究では，構造解析との連成が容易な伝 熱解析で流動解析を代用し，伝熱解析により得られる 熱の流れ方向から樹脂の流動方向を簡易的に予測し， 流動方向に基づいた異方性物性として設定する構造解 析手法を提案する.なお，伝熱解析と構造解析の連成 は，沉用構造解析ソフトで容易に実現できるが，この ような実設計に有用な手法はこれまで提案されていな b.

伝熱解析による流動方向予測の検証のため, X 線 CTで繊維方向を観察した。さらに，本手法をプロぺ ラファンの静解析および固有值解析に適用し，本手法 の妥当性検証を行った。

\section{2. 流動方向予測と構造解析との連成}

$2 \cdot 1$ 伝熱解析による流動方向予測 基本となる エネルギー方程式は，直交表座標系で式(1)のように 表される。 


$$
\begin{aligned}
& \rho c\left(\frac{\partial T}{\partial t}+V_{x} \frac{\partial T}{\partial x}+V_{y} \frac{\partial T}{\partial y}+V_{z} \frac{\partial T}{\partial z}\right) \\
& =\left(K_{x} \frac{\partial^{2} T}{\partial x^{2}}+K_{y} \frac{\partial^{2} T}{\partial y^{2}}+K_{z} \frac{\partial^{2} T}{\partial z^{2}}\right) \\
& \quad-T\left(\frac{\partial P}{\partial T}\right)\left(\frac{\partial V_{x}}{\partial x}+\frac{\partial V_{y}}{\partial y}+\frac{\partial V_{z}}{\partial z}\right) \\
& +\left(\tau_{x x} \frac{\partial V_{x}}{\partial x}+\tau_{y y} \frac{\partial V_{y}}{\partial y}+\tau_{z z} \frac{\partial V_{z}}{\partial z}\right) \\
& +\left\{\begin{array}{l}
\tau_{x y}\left(\frac{\partial V_{x}}{\partial y}+\frac{\partial V_{y}}{\partial x}\right)+\tau_{x z}\left(\frac{\partial V_{x}}{\partial z}+\frac{\partial V_{z}}{\partial x}\right) \\
+\tau_{y z}\left(\frac{\partial V_{y}}{\partial z}+\frac{\partial V_{z}}{\partial y}\right)
\end{array}\right\}+Q
\end{aligned}
$$

ここで, $x, y, z$ は, $x-y$ 平面を平板面に, $z$ 軸を板 厚方向にとった局所座標系である。

$$
\begin{aligned}
\rho & : \text { 密度 } \mathrm{kg} / \mathrm{m}^{3} \\
c & : \text { 比熱 } \mathrm{J} /(\mathrm{kg} \cdot \mathrm{K}) \\
T: \text { 温度 } & \mathrm{K} \\
t & : \text { 時間 } \mathrm{s}
\end{aligned}
$$

$V_{x}, V_{y}, V_{z}$ : 伝導媒体中の熱の速度 $\mathrm{m} / \mathrm{s}$

$K_{x}, K_{y}, K_{z}$ : 熱伝導率 $\mathrm{W} /(\mathrm{m} \cdot \mathrm{K})$

$P$ :圧力 $\mathrm{Pa}$

$\tau$ : 世ん断応力 $\mathrm{Pa}$

$Q$ : 単位体積あたりの内部発熱量 $\mathrm{W} / \mathrm{m}^{3}$

式(1)の右辺第 1 項〜第 5 項はそれぞれ, 熱伝導, 圧縮による内部エネルギー, 法線応力による仕事, せ ん断応力による仕事, 内部発熱を表す. 式 (1) から伝 熱解析に関連する項を取り出した熱伝導の支配微分方 程式は，式(2)のように表される.

$$
\begin{aligned}
& \rho c\left(\frac{\partial T}{\partial t}+V_{x} \frac{\partial T}{\partial x}+V_{y} \frac{\partial T}{\partial y}+V_{z} \frac{\partial T}{\partial z}\right) \\
& \quad=K_{x} \frac{\partial^{2} T}{\partial x^{2}}+K_{y} \frac{\partial^{2} T}{\partial y^{2}}+K_{z} \frac{\partial^{2} T}{\partial z^{2}}+Q
\end{aligned}
$$

なお，モデル形状が薄肉の場合, 板厚方向の流速成 分 $V_{z}$ および面方向の熱伝導率 $K_{x}, K_{y}$ は無視できる ため，式（３）に簡略化される.

$$
\rho c\left(\frac{\partial T}{\partial t}+V_{x} \frac{\partial T}{\partial x}+V_{y} \frac{\partial T}{\partial y}\right)=K_{z} \frac{\partial^{2} T}{\partial z^{2}}+Q
$$

同様に, 射出成形 CAE における流動解析では, 式 (4)に簡略化される(10)(11).

$$
\begin{aligned}
& \rho c\left(\frac{\partial T}{\partial t}+V_{x} \frac{\partial T}{\partial x}+V_{y} \frac{\partial T}{\partial y}\right)=K_{z} \frac{\partial^{2} T}{\partial z^{2}}+\tau_{x z} \frac{\partial V_{x}}{\partial z} \\
& +\tau_{y z} \frac{\partial V_{y}}{\partial z}+Q
\end{aligned}
$$

式 (3)と式 (4)を比較すると, 伝熱解析では, 流動 解析における板厚方向の速度勾配成分のせん断応力の 影響が含まれていないことがわかる。

したがって，せん断応力を無視できる場合，すなわ

\section{Set the position of gate}

Set the gate one temperature and the others uniform.

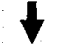

2. Run thermal analysis

Obtain the heat flow direction.

3. Define anisotropic properties based on flow direction

- Define properties for both MD and TD.

- Change element coordinate systems where heat flow direction equals MD.

4. Run structural analysis

Fig. 1 Structural analysis flow that considers fiber orientation

ち，せん断応力を決定する粘度およびせん断速度を無 視できる場合に, 流動解析を伝熱解析で簡易的に近似 できる.ここで, 粘度は, せん断速度, 温度および圧 力の関数で表されるため，これらが大きく変化しない 単純な形状; 例えば樹脂流動入口(グート)数が少ない, 板厚の増減が少ない形状，流動先端から離れた領域や 金型壁面から遠い成形品内部等に対しては, 流動の方 向つまり $V_{x}$ と $V_{y}$ の比を得るための手段として伝熱 解析を用いることは実設計において有効といえる。

汎用構造解析ソフトの伝熱解析で流動方向を予測す るには，全体をある温度に設定し，ゲート位置にそれ より高い温度を負荷する過渡熱解析を行うことによ り, 熱の流れ方向が得られるため, 得られた熱の流れ 方向を流動方向に扔きかえ, $2 \cdot 2$ 項に示す構造解析を 実施することにより, 流動方向を考慮した構造解析が 可能となる。

$2 \cdot 2$ 流動方向を考慮した構造解析 本構造解析 では，得られた流動方向に基づき異方性物性として設 定する，構造解析におけるそれぞれの要素ごとに, 流 動方向に MDの物性值, その垂直方向にTDの物性 值を設定する。繊維含有率の高い樹脂においては, $\mathrm{MD}$ と TD の弾性率が数倍異なることから，このよう に異方性物性として設定することで, 構造解析の精度 が向上する. 図 1 に, 伝熱解析と構造解析のこれらの フローをまとめて示す。

\section{3. プロペラファンの流動方向予測と検証}

$3 \cdot 1$ プロペラファンの流動方向予測 プロペラ ファンの流動方向を予測するため，汎用 FEM 解析ソ フトANSYS 11.0 (12) 用いて過渡熱解析を実施し た。解析モデルを図 2 に示す。要素はソリッド要素 （87 番：四面体，10 節点）を用い，メッシュサイズは 3 


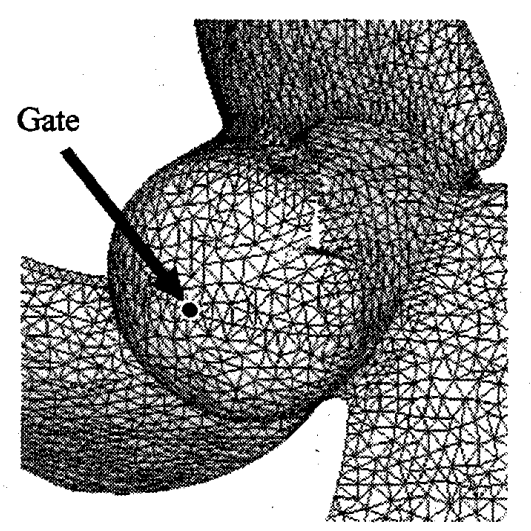

(54,427 nodes, 27,246 elements)

Fig. 2 FEM model

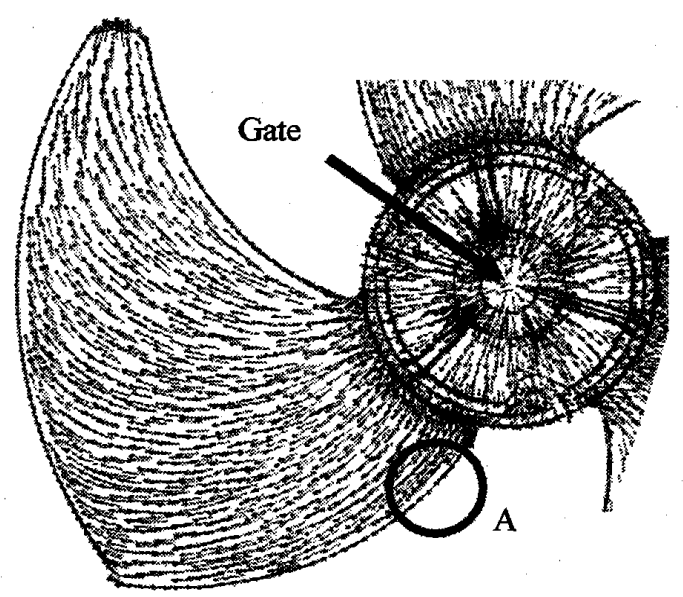

Fig. 3 Distribution of heat flux vector

$\mathrm{mm}$ とした。境界条件として，全節点に温度 0 を，゙゙ 一ト部に相当する節点に温度 1 を与えた。解析時間 は, Pentium4 3.2 GHz のパソコンで約 1 分である.

過渡熱解析により得られた熱流束べクトル分布を図 3 に示す. 熱の流れ方向は, ゲート位置から放射状に 広がる挙動を示している。なお，沉用樹脂流動解析ソ フト Mold Plastics Insight 5.1 を用いて得られた樹 脂の流動方向と本結果はほぼ一致していることを確認 している.

$3 \cdot 2$ 流動方向の妥当性検証 予測した流動方向 と実機の流動方向を比較し, 妥当性を検証する. 緘維 配向と樹脂流動の方向はおおむね一致する(13)(14)こと から, 実機の流動方向の観察は, X 線 CT 装置 (XVA-160CT：ユニハイトシステム社)を用いて,プ ロペラファンの繊維配向状態を透過撮影で観察した。

図 4 に, 撮影画像の一例として, 図 3 のA 部における 拡大写真を示す。ここで, 撮影画像において複数観察 される黒色の線状の物体が繊維である. 図 4 に示す例

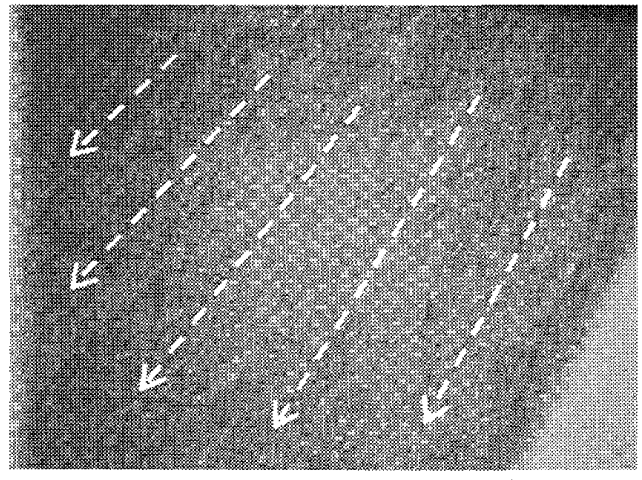

Fig. 4 A picture by X-ray CT scanner

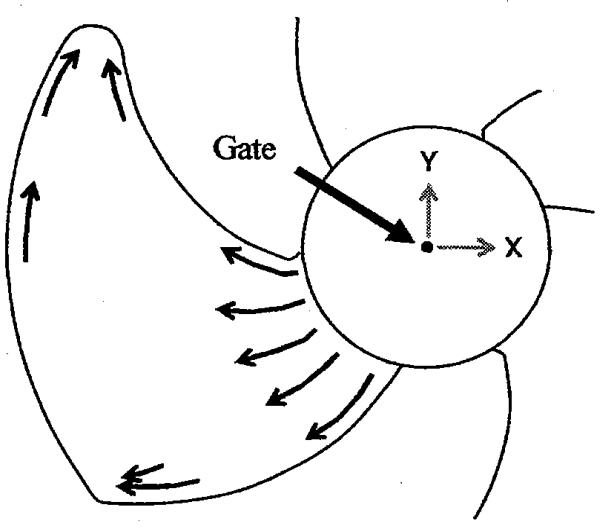

Fig. 5 Schematic diagram of fiber orientation

の場合，ゲート位置が画像の右上方向にあるため，画 像の右上から左下に向かって繊維が配向しているのが 観察できる.

同様に，プロペラファンのブレードの任意の籄所に ついて繊維の配向方向を観察し, 図 5 に示す繊維配向 方向の模式図を得た。得られた繊維配向模式図と図 3 に示す熱の流れ方向を比較すると，実機での瀻維配向 方向と熱の流れ方向はほぼ一致しており，伝熱解析に よる流動方向予測の妥当性を確認できた.

\section{4. プロペラファンの構造解析と検証}

$4 \cdot 1$ 静解析と妥当性検証 流動方向を考慮した 構造解析を行うため, $3 ・ 1$ 節で予測した流動方向を構 造解析における材料定数に反映させる。ここで, 解析 モデル形状は $3 \cdot 1$ 節と同じであり, あらかじめ定義し た要素座標系(右手則の直交座標系：xyz)に基づき, 各要素の主軸 $(x)$ 方向を, 伝熱解析により得られた熱 の流れ方向に一致させた。これにより，構造解析に抢 いて, 流動方向の弾性率を MD の弾性率として設定す ることが可能となる。

静解析に使用した温度 $20^{\circ} \mathrm{C}$ における材料定数を表 1 に示す。なお，弾性率の実験的評価には JIS 試験片を 
Table 1 Material constants for static analysis

\begin{tabular}{|c|c|c|c|c|}
\hline \multirow{2}{*}{$\begin{array}{l}\text { Case of } \\
\text { analysis }\end{array}$} & \multicolumn{2}{|c|}{$\begin{array}{c}\text { Elastic modulus } \\
\text { [GPa] }\end{array}$} & \multirow{2}{*}{$\begin{array}{c}\text { Poisson's } \\
\text { ratio } \\
{[-]} \\
\end{array}$} & \multirow{2}{*}{$\begin{array}{l}\text { density } \\
{\left[\mathrm{kg} / \mathrm{m}^{3}\right]}\end{array}$} \\
\hline & $\mathrm{MD}$ & TD & & \\
\hline 1 : isotropic & \multicolumn{2}{|c|}{3.58} & \multirow{2}{*}{0.35} & \multirow{2}{*}{1040} \\
\hline 2:anisotropic & 3.58 & $1.75^{\star}$ & & \\
\hline
\end{tabular}

$※ W_{f}=0.2, d_{f}=2700, d_{c}=1040, E_{f}=70, E_{m}=1.62$

用いるが，その試験片の長手方向を流動方向にするこ とが多く, その場合, 弾性率は MDの值になる. 解析 ケース 1 では，等方性材料物性として JIS 試験片の弾 性率, 解析ケース 2 では, 異方性材料物性として, MD の弾性率 $E_{\mathrm{MD}}$ を JIS 試験片の值とし, TDの弾性率 $E_{\mathrm{TD}}$ を式 (5)に示す複合強化則 (Ruess 則)を適用して 算出した理論値とした。複合則では, 通常ポアソン比 も変化するが, 簡単のためここでは均一材の值を用い た。

$$
\frac{1}{E_{\mathrm{TD}}}=\frac{V_{f}}{E_{f}}+\frac{1-V_{f}}{E_{m}} .
$$

ここで,

$V_{f}:$ 繊維体積含有率

$E_{f}$ : 繊維の弾性率 $\mathrm{GPa}$

$E_{m}$ : 樹脂の弾性率 $\mathrm{GPa}$

また， $V_{f}$ は, 式(6)より求められる.

$$
V_{f}=W_{f} \times \frac{d_{c}}{d_{f}}
$$

ここで,

$W_{f}$ : 䋊維重量含有率

$d_{f}$ : 繊維の密度 $\mathrm{kg} / \mathrm{m}^{3}$

$d_{c}$ : 複合材料の密度 $\mathrm{kg} / \mathrm{m}^{3}$

なお，異方性材料物性に扔けるせん断弾性係数 $G_{x y}$, $G_{y z}, G_{z x}$ についても本来は異方性を考慮する必要が あるが, 簡単のためここでは弾性率とせん断弾性係数 との関係が等方性材料と等価と仮定し，ポアソン比 を用いて式（7)，（8）により算出した。

$$
\begin{aligned}
G_{x y} & =\frac{E_{\mathrm{MD}}}{2(1+\nu)} \cdots \cdots \\
G_{y z} & =G_{z x}=\frac{E_{\mathrm{TD}}}{2(1+\nu)}
\end{aligned}
$$

要素はソリッド要素 (187 番：四面体, 10 節点)を用 いた，負荷は，図 6 に示すように，ファン中央部円筒 端面に強制変位 $1 \mathrm{~mm}$ を与え，拘束条件は，ブレード 先端 (3 節点) の軸方向 (UZ) 拘束, モデル中央であるゲ ート部の面方向 (UX, UY) 拘束とした. 解析時間は, Pentium4 $3.2 \mathrm{GHz}$ のパソコンで，異方性材料物性設 定および構造解析についてそれぞれ約 1 分である.

図 7 に, 解析結果および同条件を模擬した圧縮試験

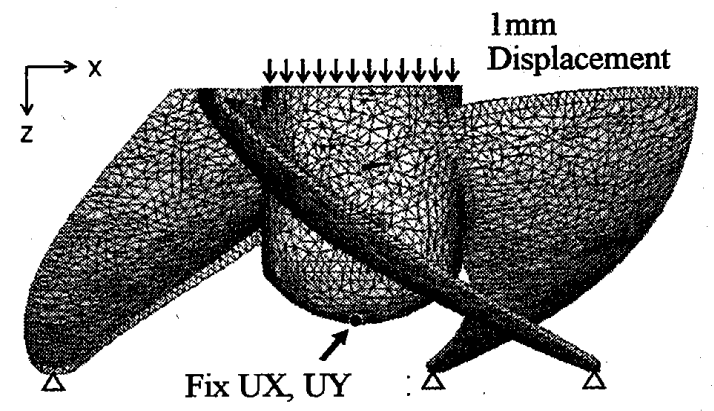

Fig. 6 Boundary condition for static analysis

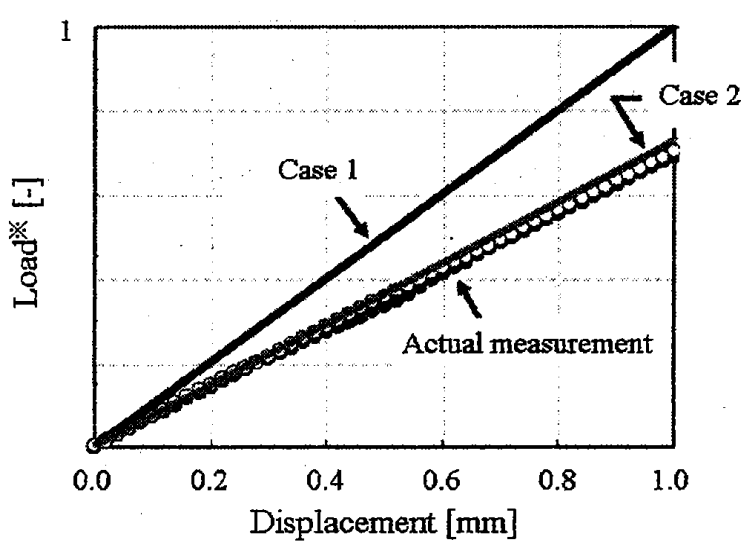

※ Normalized value;

\begin{tabular}{|c|c|c|c|c|}
\hline \multirow{2}{*}{$\begin{array}{l}\text { Case of } \\
\text { analysis }\end{array}$} & \multicolumn{2}{|c|}{$\begin{array}{c}\text { Elastic modulus } \\
\text { [GPa] }\end{array}$} & \multirow{2}{*}{$\begin{array}{c}\text { Poisson's } \\
\text { ratio } \\
{[-]}\end{array}$} & \multirow{2}{*}{$\begin{array}{l}\text { density } \\
{\left[\mathrm{kg} / \mathrm{m}^{3}\right]}\end{array}$} \\
\hline & $\mathrm{MD}$ & TD & & \\
\hline 1 : isotropic & \multicolumn{2}{|c|}{3.96} & \multirow{2}{*}{0.35} & \multirow{2}{*}{1040} \\
\hline 2:anisotropic & 3.96 & $1.93^{※}$ & & \\
\hline
\end{tabular}
the load when $1 \mathrm{~mm}$ displaced in Case 1 is 1

Fig. 7 Comparison in load-displacement curves

Table 2 Material constants for modal analysis

から得られた荷重-変位線図を示す。図中の黒丸およ び白丸は，同一サンプルを 2 回湘定した実測点であり， 実線は，前項までに述べた条件で線形解析を実施した 結果である，実測結果は，流動方向を考慮した解析ケ ース 2 の結果とほぼ同等であることが確認できる。一 方，流動方向を考慮せず，等方性物性を用いた解析ケ ース 1 に扔いては，実測結果と大きく異なっており， 等方性物性による推定では，実機より剛性を高く予測 することになる.

$4 \cdot 2$ 固有值解析と検証 次に, 流動方向を考慮 した固有值解析について検討する. 固有値解析に使用 した温度 $17^{\circ} \mathrm{C}$ 材料定数を表 2 に示す．また, 解析乇 デルは静解析と同様であり, Ansys 11.00ブロック ランチェス法を用いて固有値を求めた。解析時間は, 


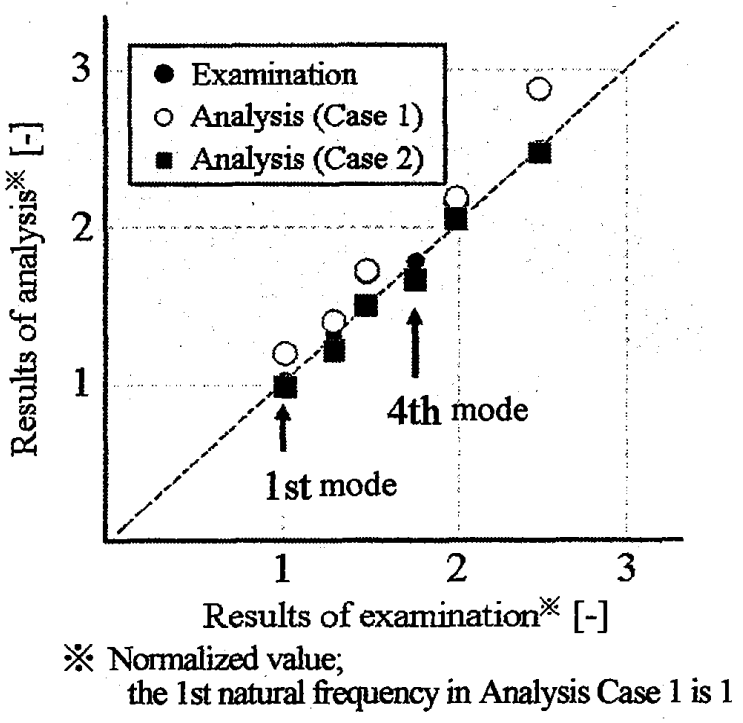

Fig. 8 Relationship between analysis and examination of natural frequencies

Pentium4 3.2 GHz のパソコンで, 約 5 分である.

図 8 に, 解析により得られた固有值と振動試験によ り得られた実機の固有值の関係を示す。破線は, 実機 と解析の固有值が一致する線である。いずれのモード においても, 流動方向を考慮した解析ケース 2 の結果 と実測結果はほぼ一致している。一方, 流動方向を考 慮せず，等方性物性を用いた解析ケース 1 においては， 実測結果と大きく異なっており，さらに，実測結果お よび流動方向を考慮した解析結果で発現する4次のモ ードが存在しない。

このように, 静解析, 固有值解析ともに, 流動方向 を考慮することにより, 構造解析の精度向上が確認で きた，本手法は，汎用構造解析ソフトで容易に解析可 能なため, 幅広い製品に適用できる.今後は, 複雑な ゲート配置や複雑な形状の製品に適用し, 本手法の適 用範囲を明確にする。

\section{5. 結訔}

繊維強化樹脂製品に対して, 沉用構造解析ソフトで 解析可能な伝熱解析で流動方向を簡易的に予測し, 流 動方向を異方性物性として設定する構造解析手法を提 案し, その妥当性について検討した. さらに, 本手法 をプロペラファンの静解析および固有值解析に適用 し, 以下の結論を得た。

（1） X 線 CT による瀻維方向観察により, 伝熱解 析で得られる熱の流れ方向と流動方向がほぼ一致する ことを確認した。

（2）プロペラファンの静解析に適用し, 流動方向
を考慮した静解析結果と実機荷重試験の結果が良く一 致した。同様に，プロペラファンの固有值解析におい ても, 流動方向を考慮した固有値解析結果と実機固有 値が良く一致した。

\section{文，献}

(1) Tohgo, K., Ishii, H. and Nobayashi, F., Transactions of the Japan Society of Mechanical Engineers, Series A, Vol. 59, No. 557 (1993), pp. 62-67.

(2) Yasuhara, T., Araki, Y., Aihara, H., Ito, H., Saito, T., Marukami, H. and Ohtake, N., Mechanical Properties of Carbon Nanofiber Reinforced Composites and Fiber Orientation Behavior in Thin-Wall Injection Molding, Proceeding of the Korea-Japan Plastics Processing Joint Seminar 2006, Vol. 1, No.1 (2006-9), pp. 25-28.

(3) Oka, H., Narita, R., Akiniwa, Y. and Tanaka, K., LowCycle-Fatigue Characteristics of Short Glass Fiber Reinforced Polybuthyleneterepthalate, Journal of the Society of Materials Science, Japan, Vol. 56, No. 5 (2007), pp. 406-413.

(4) Gupta, M. and Wang, K. K., Fiber orientation and mechanical properties of short-fiber-reinforced injection-molded composites: Simulated and experimental results, Polymer Composites, Vol. 14, No. 5 (1993), pp. 367-382.

(5) Uzawa, K., Composites Science/Technology and New Challenges for Tomorrow's Applications 1: Present and Future State of FRP Processing, Journal of the Society of Materials Science, Japan, Vol.55, No. 1 (2006), pp. 131-137.

(6) Takano, N., Asai, M., Oyama, T. and Ogawa, T., Composites Science/Technology and New Challenges for Tomorrow's Applications 2: Simulation-Based Design of Composite Materials and Structures, Poly. mer Composites, Vol. 55, No. 2 (2006), pp. 237-242.

(7) De Frahan, H. H., Verleye, V., Dupret, F. and Crochet, M. J., Numerical prediction of fiber orientation in injection molding, Polymer Engineering \& Science, Vol. 32, No. 4 (1992), pp. 254-266.

(8) Chung, S. T. and Kwon, T. H., Numerical simulation of fiber orientation in injection molding of short-fiberreinforced thermoplastics, Polymer Engineering \& Science, Vol. 35, No. 7 (1995), pp. 604-618.

(9) Foss, P. T., Coupling of flow simulation and structural analysis for glass-filled thermoplastics, Polymer Composites, Vol. 25, No.4 (2004), pp. 343-354.

(10) Hele-Shaw, H.S., Transactions, Institute of Architecture, Vol. 11, No. 25 (1989).

(11) Schlichting, H., Boundary Layer Theory, 6th ed., (1968), McGraw-Hill, New York.

(12) Ansys 11.0 online manual, (2007), Ansys, Inc.

(13) Nakano, R., Shiota, T., Hirakimoto, A., Taki, K., Takashio, H. and Chean, Y.-S., Fiber Orientation Observation by X-ray CT and Simulation, Journal of the Japan Society of Polymer Processing, Vol. 20, No. 4 (2008), pp. 237-241.

(14) Fujita, A., Baba, F., Ishida, H., Nakai, A. and Hamada, H., Estimation of Mechanical Properties of Injection Molded CF/LCP Thin Plates Using Fiber Orientation Distributions, Journal of the Japan Society of Polymer Processing, Vol. 13, No. 10 (2001), pp. 700-703. 